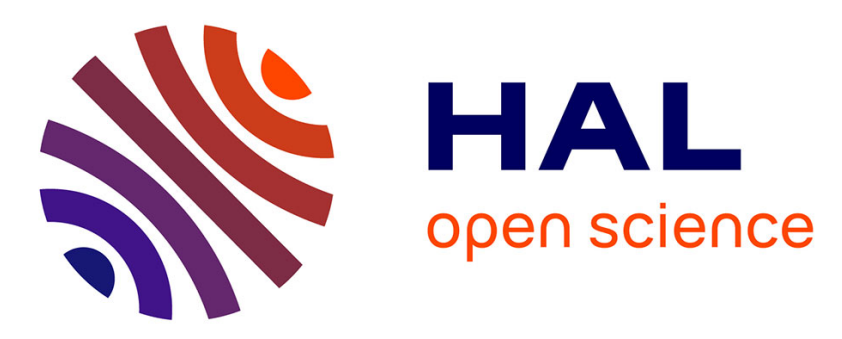

\title{
Akt signaling pathway: a target for radiosensitizing human malignant glioma
}

Emmanuel Chautard, Gaëlle Loubeau, Andrei Tchirkov, Jacques Chassagne, Claudine Vermot-Desroches, Laurent Morel, Pierre Verrelle

\section{- To cite this version:}

Emmanuel Chautard, Gaëlle Loubeau, Andrei Tchirkov, Jacques Chassagne, Claudine VermotDesroches, et al.. Akt signaling pathway: a target for radiosensitizing human malignant glioma. Neuro-Oncology, 2010, 12 (5), pp.434-443. 10.1093/neuonc/nop059 . hal-01636179

\section{HAL Id: hal-01636179 https://hal.science/hal-01636179}

Submitted on 17 Nov 2017

HAL is a multi-disciplinary open access archive for the deposit and dissemination of scientific research documents, whether they are published or not. The documents may come from teaching and research institutions in France or abroad, or from public or private research centers.
L'archive ouverte pluridisciplinaire HAL, est destinée au dépôt et à la diffusion de documents scientifiques de niveau recherche, publiés ou non, émanant des établissements d'enseignement et de recherche français ou étrangers, des laboratoires publics ou privés. 
Akt signaling pathway: a target for radiosensitizing human malignant glioma

\section{Emmanuel Chautard, Gaëlle Loubeau, Andreï Tchirkov, Jacques Chassagne, Claudine Vermot-Desroches, Laurent Morel, and Pierre Verrelle}

Centre Jean Perrin, Laboratoire de Radio-Oncologie Expérimentale, EA 3846: Thérapie Ciblée Combinatoire en Onco-Hématologie - Université d'Auvergne, 58 rue Montalembert, Clermont-Ferrand, 63001, France (E.C., G.L., A.T., J.C., P.V.) Laboratoire d'Hématologie Biologique, CHU et Centre Jean Perrin, Clermont Ferrand, 63001, France (J.C.) ; OPi EUSA Pharma, 27 chemin des Peupliers, 69570 Dardilly France (C.VD.) ; GReD, Génétique Reproduction et Développement, UMR-CNRS 6247 - Clermont Université, 63177 Aubière, France (L.M.)

Running head: Akt down modulation radiosensitizes malignant glioma

Address correspondence to: Emmanuel CHAUTARD, Centre Jean Perrin, Laboratoire de Radio-oncologie Expérimentale, EA 3846: Thérapie Ciblée Combinatoire en OncoHématologie - Université d'Auvergne, 58 rue Montalembert, Clermont-Ferrand, 63001, France. Tel : +33.4.73.27.81.42; Fax : +33.4.73.27.81.25; E-mail : 


\begin{abstract}
Radiation therapy plays a central role in the treatment of glioblastoma, but it is not curative due to the high tumour radioresistance. PI3K/Akt and JAK/STAT3 pathways serve to block apoptosis process, keeping cells alive in very toxic environments as chemotherapy or ionizing radiation. In the present study, from a panel of 8 human malignant glioma cell lines, firstly investigations on the relationship between intrinsic radioresistance and Akt or STAT3 basal activation were done. Secondly, the impact of down modulation of Akt or STAT3 signaling on in vitro intrinsic radiosensitivity was evaluated. Using clonogenic cell survival assay, our results revealed a significant correlation between basal Akt activation and Surviving Fraction at 2 Gy (SF2). By contrast, no correlation was found between STAT3 activation and SF2. According to this, down modulation of Akt with a specific chemical inhibitor (Akt inhibitor IV) demonstrated a significant enhancement of radiation sensitivity on glioma cells in clonogenic survival assay. On the contrary, down modulation of STAT3 signaling with a specific chemical inhibitor (JSI-124) or a neutralizing gp130 antibody failed to radiosensitize glioma cells. These data indicate that Akt intercept node could be a more relevant therapeutic target than STAT3 for radiosensitizing human malignant glioma.
\end{abstract}

Keywords: Human malignant glioma, intrinsic radioresistance, Akt signaling pathway, STAT3 signaling pathway. 


\section{Introduction}

Gliomas are the most common primary tumors of the central nervous system. ${ }^{1-3}$ Among these tumors, the most frequent and malignant type is glioblastoma (GBM). Glioblastomas have been described as rapidly growing tumors associated with necrosis and endothelial proliferation. These neoplasms are extremely resistant to treatment, including radiotherapy and/or chemotherapy, and patient median survival does not exceed 1 year. ${ }^{4,5}$

Although radiotherapy increases patient survival, this treatment is not curative because of tumor regrowth inside the irradiated tumor volume. ${ }^{6-8}$ This might be explained by the fact that interactions between tumor and microenvironnement are involved in tumoral radioresistance through angiogenesis, ${ }^{9}$ hypoxia ${ }^{10}$ and immunosuppression. ${ }^{11,12}$ Another part of tumor radioresistance is due to intrinsic radioresistance of tumor cells themselves. A molecular analysis in tumor samples of basal activation of different signaling pathway potentially involved in radioresistance could be of clinical interest. Phosphatidyl-inositol 3kinase (PI3K) / Protein Kinase B (Akt) and Janus Kinase (JAK) / Signal Transducer and Activator of Transcription (STAT) pathways serve to block apoptosis process, keeping cells alive in very toxic environments as chemotherapy or ionizing radiation (IR). ${ }^{13,14}$ In a bioclinical prospective study, Chakravarti et al. showed a significant correlation between the level of basal Akt phosphorylation and a poor prognosis in human glioma in a subset of patients treated by radiotherapy only. ${ }^{15}$ Rahaman et al. reported experimental data demonstrating that inhibition of STAT3 signaling pathway was also associated with increased apoptosis and proliferation inhibition in malignant glioma. ${ }^{16}$ 
The development of Akt and STAT3 inhibitors has been a goal of pharmaceutical companies since the discovery that these pathways are often activated in numerous human cancer such as melanoma, myeloma, brain cancer, breast cancer and ovarian cancer. ${ }^{17,18}$ Combining drugs with radiation is common in cancer treatment, and aim at achieving better therapeutic effects than with single-modality therapy. Several chemical in vitro inhibitors have been developped against Akt ${ }^{17}$ or STAT3. ${ }^{19}$ Akt Inhibitor IV (5-(2-Benzothiazolyl)-3ethyl-2-[2-(methylphenylamino)ethenyl]-1-phenyl-1H-benzimidazolium iodide) inhibits Akt phosphorylation by targeting the ATP binding site of a kinase upstream of Akt, but downstream of PI3K. ${ }^{20}$ Akt inhibitor IV sensitized human leukemic HL-60 cells to TRAIL (TNF-related apoptosis-inducing ligand). ${ }^{21}$ JSI-124, Cucurbitacin I, is a triterpenoid compound that acts as a highly selective inhibitor of JAK/STAT3 signaling pathway. ${ }^{22}$ JSI124 was recently shown to sensitize malignant glioma and medulloblastoma cells to temozolomide, 1,3-bis(2-chloroethyl)-1-nitrosourea and to cisplatin, with a synergy between JSI-124 and cisplatin. ${ }^{23}$

Here, we studied in human malignant glioma cell lines: (I) the relationship between intrinsic radioresistance and Akt or STAT3 basal activation; and (II) the impact of down modulation of Akt or STAT3 signaling on in vitro intrinsic radiosensitivity. Down modulation of Akt with a chemical inhibitor (Akt inhibitor IV) demonstrated a significant enhancement of radiation sensitivity on glioma cells in clonogenic survival assay. On the contrary, down modulation of STAT3 signaling with a chemical inhibitor (JSI-124) or a neutralizing gp130 antibody failed to radiosensitize glioma cells. The radioresistance was evaluated using clonogenic cell survival assay and the basal level of activation of signaling pathways using Western blot. These data indicate that Akt intercept node could be a more relevant therapeutic target than STAT3 for radiosensitizing human malignant glioma. 


\section{Methods and Materials}

Materials - Akt (No 9272), phospho-Akt Ser473 (No 9271), STAT3 (No 4904), and phospho-STAT3 Tyr705 (No 9145) rabbit antibodies were from Ozyme (Saint Quentin Yvelines, France). Control rabbit IgG (No I5006) and $\beta$-actin (No A2066) were from Sigma (Saint Quentin Fallavier, France). Anti rabbit-FITC was from Dako (No F0054, Trappes, France) and anti rabbit-peroxidase was from P.A.R.I.S. (Compiègne, France). All culture reagents were purchased from GIBCO (Invitrogen, Cergy-Pontoise, France). Gp130 blocking antibody (No 852.060.000) and control (IgG2a, No 857.080.000) mouse antibody are from Diaclone (Besançon, France).

Cell culture - Eight human malignant glioma cell lines were used in this study. SF763, SF767 and U251MG cell lines were kindly provided by Dr C. Delmas (Centre de Lutte Contre le Cancer Claudius Regaud, Toulouse, France). SW1783, SNB19, and U373MG were obtained from N. Auger (Institut Curie, Paris, France). T98G and CB193 cell lines were kindly provided by G. Pennarun (CEA, Grenoble, France). All cell lines were cultured in DMEM (with 4500mg/l glucose and L-glutamine) supplemented with Sodium Pyruvate 1\%, Non Essential Amino Acids 1\%, Gentamicin 10 $\mathrm{g} / \mathrm{ml}$ and $10 \%$ Foetal Calf Serum in a humidified incubator containing $5 \% \mathrm{CO} 2$ at $37^{\circ} \mathrm{C}$. All cell lines were mycoplasm free after treatment with plasmocin (Invivogen, Toulouse, France).

Clonogenic cell survival assay - Cells in exponential phase of growth were trypsinised with a $0.25 \%$ Trypsin-PBS solution and were seeded at 1000 to 4000 cells per T25 flask. One day after, three flasks were irradiated per dose and irradiation was performed as single exposure doses delivered by a linear accelerator at room temperature. After 9 days of 
incubation, the content of the flasks were fixed with methanol and stained with a Giemsa stain solution (5\%). The Plating Efficiency (PE) represents the percentage of cells seeded that grow into colonies of a given cell line. Colonies with more than 50 cells were counted by microscopic inspection, and plating efficiency as well as the radiation-surviving fraction (plating efficiency of experimental group/ plating efficiency of control group) was determined. Each experiment was repeated on three separate days, and each day triplicates of each dose were performed. The intrinsic radiosensitivity was evaluated by using two parameters: the Surviving Fraction at 2 Gy (SF2) and the Area Under survival Curve (AUC). Survival curves were obtained by combinating data from three independent experiments (separate days) in accordance with linear-quadratic model (KaleidaGraph software 4.0).

Western blot - Cells in exponential phase of growth were harvested using Buffer C ( supplemented with NP-40, phosphatase inhibitors (NaF, Na2VO3) and protease inhibitor IP25X (Roche). Total proteins $(30 \mu \mathrm{g})$ were boiled in Laemmli sample buffer and subjected to SDS-PAGE. Proteins were then transferred to nitrocellulose membranes (Hybond ECL, Amersham Biosciences) followed by blocking in Tris-buffered saline 1X, 10\% powdered milk, and incubated with indicated antibodies in the same buffer overnight at $4^{\circ} \mathrm{C}$. Membranes were washed three times with $1 \mathrm{X}$ Tris-buffered saline, $0.05 \%$ Tween 20 , and then incubated $1 \mathrm{~h}$ with anti-rabbit (P.A.R.I.S) peroxidase-conjugated IgG. Detection was performed using ECL system (PerkinElmer Life Sciences). Three independent experiments were used for analysis with Quantity One (BioRad).

Chemical Akt and STAT3 inhibitors - Akt Inhibitor IV (B2311) was from Sigma and STAT3 inhibitor (JSI-124) was from Calbiochem (VWR, Fontenay Sous Bois, France). Stock solutions of Akt inhibitor IV $(81.3 \mu \mathrm{M})$ and of JSI-124 $(19 \mu \mathrm{M})$ were constituted using DMSO 
and stored at $-20^{\circ} \mathrm{C}$. These stock solutions were diluted to the desired concentration with culture medium. For Western blot analysis, cells were exposed $7 \mathrm{~h}$ to inhibitor prior protein extraction. For clonogenic survival assay in presence of chemical inhibitors, 1000 to 4000 cells were seeded per T25 flask. One day after, cells were pre-incubated with the different inhibitors (Akt inhibitor IV, JSI-124 or DMSO) for 7h prior to irradiation and then cells were then cultured with inhibitors for up to $24 \mathrm{~h}$. Data were normalized to control (treatment with inhibitor without irradiation) to exclude effect of inhibitor alone on surviving fraction.

\section{Results}

Radiosensitivity analysis of human glioma cell lines by clonogenic cell survival - The intrinsic radiosensitivity of the glioma cell lines was investigated using standard clonogenic assay. Cell lines were irradiated with increasing doses of radiation $(0,2,4,6,8$ and $10 \mathrm{~Gy})$. SF2 and AUC were used to measure intrinsic radiosensitivity. Survival data were fitted to the linear-quadratic model (fig. 1). As shown in Table1, PE values varied from 0.05 to 0.28 . SF2 values ranged from 0.46 to 0.83 and AUC values ranged from 2.4 to 5.5. A significant correlation between SF2 and AUC ( $\mathrm{r}=0.951 ; \mathrm{p}=0.00043$; linear regression) was observed. Our data obtained are in agreement with previous results evaluating the radiosensitivity of human glioma. ${ }^{24-27}$ SF763 and SW1783 appeared to be respectively the most and the less radioresistant cell line with 0.83 and 0.46 for SF2; 5.5 and 2.4 Gy for AUC values.

Correlation between activation levels of Akt and STAT3 and radiosensitivity - Among the human glioma cell line panel, STAT3 phosphorylated Tyr705 and Akt phosphorylated Ser473 residues, which are known to be active phosphorylation sites, ${ }^{28,29}$ and STAT3 and Akt expression were analyzed by Western blot (fig. 2). Levels of activation were estimated by the 
phospho-protein/total protein expression ratio. A significant correlation was found between the pAkt/Akt ratio and SF2 $(\mathrm{r}=0.764 ; \mathrm{p}=0.027$; linear regression $)$, but not between pSTAT3/STAT3 ratio and SF2. Note that the most radioresistant cell line, SF763, exhibited a high basal activation of both Akt and STAT3 signaling pathways. On the contrary, no activation of these pathways was observed in the SW1783 cell line, which is the most sensitive to ionizing radiation.

Impact of Akt or STAT3 signaling down modulation on glioma radioresistance - We used chemical Akt and STAT3 inhibitors at lower doses that slightly affect plating efficiency in the absence of radiation in order to underline a radiosensitizing effect. In our study, the SF763 cell line exhibits an activation of both Akt and STAT3 signaling. The SF767 and SNB19 cell lines presents respecitvely only Akt and STAT3 activation pathway in basal conditions.

Firstly, SF763 cells were treated with a concentration range of Akt inhibitor IV, for $7 \mathrm{~h}$ and Akt phosphorylation was investigated using Western blot analyses. As previously reported for other cell lines, ${ }^{20}$ we observed a specific decrease of Akt activation with a dose of $10 \mu \mathrm{M}$ in SF763 cells compared to cells treated with DMSO e . We also observed a lower decrease of Akt activation with 0.2 and $5 \mu \mathrm{M}$ (fig. 3A). Akt inhibitor IV, decreased PE in SF763 cells after $24 \mathrm{~h}$ of exposure, in a dose dependent manner ranging from 0.86 for $0.2 \mu \mathrm{M}$ to 0.63 for $0.04 \mu \mathrm{M}$ (fig. 3B). When SF763 cells were exposed $24 \mathrm{~h}$ with $0.2 \mu \mathrm{M}$ of Akt inhibitor IV and irradiated at 4 Gy after $7 \mathrm{~h}$ of treatment, we observed a significant specific decrease in surviving fraction $(\mathrm{p}<0.01, t$-test) compared with the control (DMSO $+4 \mathrm{~Gy}$, fig. 3C). Clonogenic survival assays ranging from 0 to 10 Gy demonstrated a highly significant enhancement of radiation sensitivity ( $p<10^{-7}$, ANOVA) after treatment with $0.2 \mu \mathrm{M}$ of Akt inhibitor IV (fig. 3D). 
To confirm Akt pathway involvement in glioma cell radioresistance we carried out experiments to know if down-modulation of Akt could increase radiation sensitivity of the SF767 cell line. SF767 cells were treated with a concentration range of Akt inhibitor IV, for 7h and Akt phosphorylation was investigated using Western blot. As for the SF763 cell line, we observed a specific decrease of Akt activation with a dose of $10 \mu \mathrm{M}$ in SF767 cells compared to cells treated with DMSO (control). We also observed a lower decrease of Akt activation with $0.1 \mu \mathrm{M}$ (fig. 4A). Akt inhibitor IV, decreased PE in SF767 cells after 24h of exposure, in a dose dependent manner ranging from 0.87 for $0.05 \mu \mathrm{M}$ to 0.20 for $0.3 \mu \mathrm{M}$ (fig. 4B). When SF767 cells were exposed $24 \mathrm{~h}$ with $0.1 \mu \mathrm{M}$ of Akt inhibitor IV and irradiated at 2 Gy after $7 \mathrm{~h}$ of treatment, we observed a significant specific decrease in surviving fraction $(\mathrm{p}<$ 0.05, $t$-test) compared with the control (DMSO +2 Gy, fig. 4C). Clonogenic survival assays ranging from 0 to $10 \mathrm{~Gy}$ demonstrated a significant enhancement of radiation sensitivity $(\mathrm{p}<$ $10^{-3}$, ANOVA) after treatment with $0.1 \mu \mathrm{M}$ of Akt inhibitor IV (fig. 4D).

Secondly, SF763 cells were treated with a concentration range of JSI-124 for $7 \mathrm{~h}$ and pSTAT3/STAT3 ratio was evaluated using Western blot analyses. As shown in fig. 5A, the exposure of cells to $0.2 \mu \mathrm{M}$ of JSI- 124 for $7 \mathrm{~h}$ induced a decrease of STAT3 pathway activation whereas lower doses seemed to have no impact. Although there was no decrease in pSTAT3 with JSI-124 $0.01 \mu \mathrm{M}$ in these experimental conditions, clonogenic survival was altered. Thus, JSI-124 after $24 \mathrm{~h}$ treatment proved to be an effective inhibitor of SF763 colony formation in vitro, in a dose dependent manner ranging from 0.87 for $0.01 \mu \mathrm{M}$ to 0.39 for $0.04 \mu \mathrm{M}$ (fig. 5B). To test a potential radiosensitizing effect of JSI-124, cells were treated with $0.01 \mu \mathrm{M}$ JSI-124 for $24 \mathrm{~h}$ including irradiation at $4 \mathrm{~Gy}$ after $7 \mathrm{~h}$ of treatment. As shown in fig. 5C, JSI-124 treatment failed to sensitize SF763 cells to ionizing radiation.

STAT3 pathway activation involves gp130 recruitment usptream JAK2 activation ${ }^{29}$ so another approach to inhibit STAT3 pathway was carried out using gp130 blocking antibody. 
The exposure of SF763 cells to anti-gp130 blocking antibody $(10 \mu \mathrm{g} / \mathrm{ml})$ did not affect plating efficiency (data not shown) but abrogated activation of STAT3 pathway after 24h of treatment as shown in figure 5D. In clonogenic survival assay, anti-gp130 or control antibody (IgG2a) was added when cells were attached in flasks ( $8 \mathrm{~h}$ after seeding), before or after irradiation until the end of experiment. In all three conditions, a decrease of STAT3 pathway activation did not radiosensitize SF763 cells (representative results fig. 5E).

Because anti-gp130 antibody treatment does not affect colony forming with a striking inhibition of STAT3 in the SF763 cell line, we used this approach to test potential radiosensitizing effect of STAT3 inhibition in the SNB19 cell line. The exposure of SNB19 cells to anti-gp130 blocking antibody $(10 \mu \mathrm{g} / \mathrm{ml})$ did not affect plating efficiency (data not shown) but abrogated activation of STAT3 pathway after $24 \mathrm{~h}$ of exposure as shown in figure 6A. In clonogenic survival assay, anti-gp130 or control antibody (IgG2a) was added when cells were attached in flasks ( $8 \mathrm{~h}$ after seeding). Despite the decrease of STAT3 pathway activation anti-gp130 antibody did not radiosensitize SNB19 cells (fig. 6B).

\section{Discussion}

Radiotherapy is a part of the gold standard treatment of glioblastomas, but these tumors are radioresistant. Targeting signaling pathways involved in GBM radioresistance may improve clinical results of radiotherapy. PI3K/Akt and JAK/STAT3 pathways are major cell survival pathways blocking apoptosis process and keeping cells alive in very toxic environments as chemotherapy or ionizing radiation. Here, we studied in human malignant glioma cell lines: (I) the relationship between intrinsic radioresistance and Akt or STAT3 basal activation; and (II) the impact of down modulation of Akt or STAT3 signaling on in vitro intrinsic radiosensitivity. 
To date, little is known about direct relationship between Akt or STAT3 activation and tumor radioresistance. Our results showed significant correlation between basal Akt activation and Surviving Fraction at 2 Gy (SF2). Conversely, no such correlation was established between STAT3 activation and SF2 suggesting that Akt is a survival pathway associated with radioresistance. In our study, the most radioresistant glioma cell line was SF763, exhibiting an activation of both Akt and STAT3 signaling in basal conditions. SF763 was a good candidate to study effects of Akt or STAT3 down modulation on the radioresistance level. SF767 cell line presents only a high level of Akt and SNB19 cell line shows only an activation of STAT3 pathway so they are good models to study specific roles of respectively Akt and STAT3 inhibition in glioma radiosensitization.

Akt pathway down modulation and glioma radiosensitivity - Our results showed that Akt pathway activation is closely related to human glioma radioresistance. Althought IR damages tumor cells through several mechanisms, IR is thought to kill cells primarily by causing DNA damage and, specifically, double strand breaks (DSBs). Prior to undergoing division, this leads to a DNA damage response to allow repair of the DNA damage. ${ }^{30}$ The ability to repair is essential to cell survival because maintained DNA breaks induce apoptosis or senecence. ${ }^{31}$ A recent study by Kao et al. reported that PI3K/Akt signaling pathway down modulation led to persistence of unrepaired DSBs induced by radiation in a human glioblastoma cell line (U251), demonstrating that this pathway can modulate DNA damage repair in response to radiation and may be involved in radiation therapy efficiency. ${ }^{32}$ To explain this, one hypothesis could imply the DNA-dependent protein kinase (DNA-PK) which is one of the downstream targets of Akt signaling. ${ }^{33}$

The greatest improvement in tumor control will also be through the understanding of stem cells radioresistance mechanisms. Down modulation of Akt signaling induced apoptosis, 
neurosphere formation suppression, and reduced motility and invasivness in brain tumor stem cells. ${ }^{34}$ Interestingly, Akt down modulation sensitizes medullobastoma stem cells located in the perivascular region to radiation-induced apoptosis, suggesting that Akt inhibitors may be an effective anti-cancer stem cell therapy. ${ }^{35}$

Here, we showed that Akt inhibitor IV was able to inhibit in a dose dependent manner in vitro colony formation of malignant glioma cell line SF763. Clonogenic survival assays using AKT inhibitor demonstrated enhancement of radiation sensitivity when SF763 cells were exposed for $24 \mathrm{~h}$ to $0.2 \mu \mathrm{M}$ of Akt inhibitor IV. Akt pathway activation involvement in glioma cell radioresistance was confirmed by significant enhancement of radiation sensitivity of SF767 cells after treatment with $0.1 \mu \mathrm{M}$ of Akt inhibitor IV.

Many PI3K inhibitors have been developped in the last few decades to study PI3K signaling involvement in various biological process. A part of them were used to radiosensitize cancer cells, such as wortmannin ${ }^{36}$ and LY294002 $2^{37}$ but they have limited clinical utility due to their severe toxicities. This could be explained in part by the fact that such drugs target all PI3K protein family. More recently Chen et al have shown that PI-103, a novel PI3K inhibitor, with less toxic properties, could radiosensitize PTEN-mutated cell lines whereas it could not radiosensitize glioma cell lines with PTEN wild type. ${ }^{38}$ Re-establishment of PTEN was also a promising approach to radiosensitize glioma because PTEN is often mutated in these tumors. ${ }^{32,39}$ In contrast to PI- $103^{32}$ or Nelfinavir ${ }^{39}$, we reported in this work that Akt inhibitor IV radiosensitizes wild type PTEN glioma cells (SF763, SF767 ${ }^{38}$ ), but these two cell lines were selected for experiments because of their high level of radioresistance regardless their PTEN status.

STAT3 pathway down modulation and glioma radiosensitivity - JSI-124, acts as a highly selective inhibitor of the JAK/STAT3 signaling pathway. ${ }^{22} \mathrm{Su}$ et al have demonstrated 
that JSI-124 induced in glioma cells $\mathrm{G}_{(2)} / \mathrm{M}$ accumulation via downregulation of cyclin $\mathrm{B} 1$ and cdc2 expression. ${ }^{40}$ Down modulation of STAT3 signaling using JSI-124 was also associated with a decrease in local immunosuppression in a murine intracranial model of glioma. ${ }^{41}$ JSI-124 was recently shown to sensitize malignant glioma and medulloblastoma cells to temozolomide, 1,3-bis(2-chloroethyl)-1-nitrosourea, and cisplatin with a synergy between JSI-124 and cisplatin, ${ }^{23}$ but to our knowledge, there is no study evaluating the ability of JSI-124 to alter cancer cell resistance to ionizing radiation. Here, we showed that JSI-124 alone was able to inhibit SF763 cells colony formation in a dose dependent manner, but that STAT3 down modulation, either using JSI-124 or anti-gp130 blocking antibody, did not modify SF763 cells sensitivity to ionizing radiation.

Despite the decrease of STAT3 pathway activation after anti-gp130 antibody exposure no radiosensitizing effect was observed in SNB19 cells. This is consistent with the absence of correlation between STAT3 activation and radioresistance level in the tested cell lines. Moreover, a recent study reported that STAT3 can have a tumor-suppressive function that is regulated by the tumor suppressor PTEN. Nuclear constitutively activated form of Epidermal Growth Factor Receptor variant III (EGFRvIII) acts as a switch to convert this STAT3 from a tumor-suppressive to a pro-oncogenic protein. ${ }^{42}$ Altogether our results with these last data support that STAT3 involvement in glioma radioresistance remains unclear and would depend on PTEN and EGFRvIII status in glioma cells.

In summary, the results of the present study and other reports ${ }^{32,38,39}$ strongly suggest that Akt is a valid target for glioma cell radiosensitization. Our conclusions are different from those of de la Pena et al, who obtained no radiosensitization effect on glioma cells by treatment with perifosine, a drug that down regulate Akt phosphorylation. ${ }^{43}$ Further experiments are needed to understand the link between PTEN, EGFRvIII and STAT3 status in 
regard to glioma radioresistance. These data indicate that Akt intercept node could be a more relevant therapeutic target than STAT3 for radiosensitizing human malignant glioma.

The PI3K/Akt pathway could be activated by numerous cytokines or growth factors. We reported that among these activators, interleukin-6 (IL-6) gene amplification and overexpression were associated with poor survival in patients with malignant gliomas. ${ }^{44} \mathrm{We}$ have previously reported that interleukin-6 gene is amplified in SF763 but not in SF767 cell line. $^{45} \mathrm{PI} 3 \mathrm{~K} / \mathrm{Akt}$ could also be activated by EGFR which is often amplified in glioblastoma ${ }^{46,47}$ but EGFR status in these cell lines is unknown. Furthermore, receptor tyrosine kinase independent activation of the PI3K/Akt pathway is commonly observed in many cancers, and can occur through multiple mechanisms, such as mutation or amplification of PI3K gene, amplification of Akt gene, activation of an upstream oncogene (e.g., RAS), or mutation or decreased expression of the tumor suppressor PTEN. ${ }^{48}$ Because of these multiple possibilities, instead of inhibiting a single cell surface receptor, down modulation of signal transduction through such an intercept node will be a more effective approach to block radioresistance. ${ }^{49}$ The PI3K/Akt node could be a relevant therapeutic target to radiosensitize tumor cells by inhibiting both anti-apoptotic mechanisms and DNA damage repair after radiation.

\section{Acknowledgments}

This work was supported by the Ligue Nationale Contre le Cancer (Comité du Puy De Dôme) and by the Region Auvergne. We are grateful to Nicolas Foray for assistance using Kaleidagraph software; Claude Beaudoin for critical reading of the manuscript ; Michele Manin for helpful advices for cell cultures; Angélique DeHaze, Julie Dufour, Antoine Nigon and Jean-paul Saru for technical assistance. E.C. was the recipient of a fellowship from the MENESR (Ministère de l'Education Nationale de l'Enseignement Supérieur et de la Recherche). 


\section{References}

1 Legler JM, Ries LA, Smith MA, et al. Cancer surveillance series [corrected]: brain and other central nervous system cancers: recent trends in incidence and mortality. J Natl Cancer Inst. 1999;91:1382-1390

2 Gurney JG and Kadan-Lottick N. Brain and other central nervous system tumors: rates, trends, and epidemiology. Curr Opin Oncol. 2001;13:160-166

3 Ohgaki H and Kleihues P. Epidemiology and etiology of gliomas. Acta Neuropathol (Berl). 2005;109:93-108

4 DeAngelis LM, Burger PC, Green SB and Cairncross JG. Malignant glioma: who benefits from adjuvant chemotherapy? Ann Neurol. 1998;44:691-695

5 Stupp R, Mason WP, van den Bent MJ, et al. Radiotherapy plus concomitant and adjuvant temozolomide for glioblastoma. $N$ Engl J Med. 2005;352:987-996

6 Walker MD, Green SB, Byar DP, et al. Randomized comparisons of radiotherapy and nitrosoureas for the treatment of malignant glioma after surgery. $N$ Engl J Med. 1980;303:1323-1329

7 Walker MD, Strike TA and Sheline GE. An analysis of dose-effect relationship in the radiotherapy of malignant gliomas. Int J Radiat Oncol Biol Phys. 1979;5:1725-1731

8 Bleehen NM and Stenning SP. A Medical Research Council trial of two radiotherapy doses in the treatment of grades 3 and 4 astrocytoma. The Medical Research Council Brain Tumour Working Party. Br J Cancer. 1991;64:769-774

9 Shannon AM and Williams KJ. Antiangiogenics and radiotherapy. J Pharm Pharmacol. 2008;60:1029-1036

10 Bussink J, Kaanders JH and van der Kogel AJ. Tumor hypoxia at the micro-regional level: clinical relevance and predictive value of exogenous and endogenous hypoxic cell markers. Radiother Oncol. 2003;67:3-15

11 De Ridder M, Verovski VN, Darville MI, et al. Macrophages enhance the radiosensitizing activity of lipid A: a novel role for immune cells in tumor cell radioresponse. Int J Radiat Oncol Biol Phys. 2004;60:598-606

12 Apetoh L, Ghiringhelli F, Tesniere A, et al. Toll-like receptor 4-dependent contribution of the immune system to anticancer chemotherapy and radiotherapy. Nat Med. 2007;13:10501059

13 Toker A and Yoeli-Lerner M. Akt signaling and cancer: surviving but not moving on. Cancer Res. 2006;66:3963-3966

14 Hodge DR, Hurt EM and Farrar WL. The role of IL-6 and STAT3 in inflammation and cancer. Eur J Cancer. 2005;41:2502-2512

15 Chakravarti A, Zhai G, Suzuki Y, et al. The prognostic significance of phosphatidylinositol 3-kinase pathway activation in human gliomas. J Clin Oncol. 2004;22:1926-1933

16 Rahaman SO, Harbor PC, Chernova O, Barnett GH, Vogelbaum MA and Haque SJ. Inhibition of constitutively active Stat 3 suppresses proliferation and induces apoptosis in glioblastoma multiforme cells. Oncogene. 2002;21:8404-8413

17 LoPiccolo J, Granville CA, Gills JJ and Dennis PA. Targeting Akt in cancer therapy. Anticancer Drugs. 2007;18:861-874

$18 \mathrm{Yu} \mathrm{H}$ and Jove R. The STATs of cancer--new molecular targets come of age. Nat Rev Cancer. 2004;4:97-105

19 Costantino L and Barlocco D. STAT 3 as a target for cancer drug discovery. Curr Med Chem. 2008; 15:834-843 
20 Kau TR, Schroeder F, Ramaswamy S, et al. A chemical genetic screen identifies inhibitors of regulated nuclear export of a Forkhead transcription factor in PTEN-deficient tumor cells. Cancer Cell. 2003;4:463-476

21 Han H, Shin SW, Seo CY, et al. 15-Deoxy-delta 12,14-prostaglandin J2 (15d-PGJ 2) sensitizes human leukemic HL-60 cells to tumor necrosis factor-related apoptosis-inducing ligand (TRAIL)-induced apoptosis through Akt downregulation. Apoptosis. 2007;12:21012114

22 Blaskovich MA, Sun J, Cantor A, Turkson J, Jove R and Sebti SM. Discovery of JSI-124 (cucurbitacin I), a selective Janus kinase/signal transducer and activator of transcription 3 signaling pathway inhibitor with potent antitumor activity against human and murine cancer cells in mice. Cancer Res. 2003;63:1270-1279

23 Lo HW, Cao X, Zhu H and Ali-Osman F. Constitutively activated STAT3 frequently coexpresses with epidermal growth factor receptor in high-grade gliomas and targeting STAT3 sensitizes them to Iressa and alkylators. Clin Cancer Res. 2008;14:6042-6054

24 Delmas C, Heliez C, Cohen-Jonathan E, et al. Farnesyltransferase inhibitor, R115777, reverses the resistance of human glioma cell lines to ionizing radiation. Int $J$ Cancer. 2002;100:43-48

25 Daido S, Yamamoto A, Fujiwara K, Sawaya R, Kondo S and Kondo Y. Inhibition of the DNA-dependent protein kinase catalytic subunit radiosensitizes malignant glioma cells by inducing autophagy. Cancer Res. 2005;65:4368-4375

26 Russell JS, Lang FF, Huet T, et al. Radiosensitization of human tumor cell lines induced by the adenovirus-mediated expression of an anti-Ras single-chain antibody fragment. Cancer Res. 1999;59:5239-5244

27 Casper D, Lekhraj R, Yaparpalvi US, et al. Acetaminophen selectively reduces glioma cell growth and increases radiosensitivity in culture. J Neurooncol. 2000;46:215-229

28 Alessi DR, James SR, Downes CP, et al. Characterization of a 3-phosphoinositidedependent protein kinase which phosphorylates and activates protein kinase Balpha. Curr Biol. 1997;7:261-269

29 Levy DE and Darnell JE, Jr. Stats: transcriptional control and biological impact. Nat Rev Mol Cell Biol. 2002;3:651-662

30 Willers H, Dahm-Daphi J and Powell SN. Repair of radiation damage to DNA. $\mathrm{Br} J$ Cancer. 2004;90:1297-1301

31 Zhou BB and Elledge SJ. The DNA damage response: putting checkpoints in perspective. Nature. 2000;408:433-439

32 Kao GD, Jiang Z, Fernandes AM, Gupta AK and Maity A. Inhibition of Phosphatidylinositol-2-OH Kinase/Akt Signaling Impairs DNA Repair in Glioblastoma Cells following Ionizing Radiation. J Biol Chem. 2007;282:21206-21212

33 Toulany M, Dittmann K, Fehrenbacher B, Schaller M, Baumann M and Rodemann HP. PI3K-Akt signaling regulates basal, but MAP-kinase signaling regulates radiation-induced XRCC1 expression in human tumor cells in vitro. DNA Repair (Amst). 2008;7:1746-1756

34 Eyler CE, Foo WC, LaFiura KM, McLendon RE, Hjelmeland AB and Rich JN. Brain cancer stem cells display preferential sensitivity to Akt inhibition. Stem Cells. 2008;26:30273036

35 Hambardzumyan D, Becher OJ, Rosenblum MK, Pandolfi PP, Manova-Todorova K and Holland EC. PI3K pathway regulates survival of cancer stem cells residing in the perivascular niche following radiation in medulloblastoma in vivo. Genes Dev. 2008;22:436-448

36 Norman BH, Shih C, Toth JE, et al. Studies on the mechanism of phosphatidylinositol 3kinase inhibition by wortmannin and related analogs. J Med Chem. 1996;39:1106-1111 
37 Gupta AK, Cerniglia GJ, Mick R, et al. Radiation sensitization of human cancer cells in vivo by inhibiting the activity of PI3K using LY294002. Int J Radiat Oncol Biol Phys. 2003;56:846-853

38 Chen JS, Zhou LJ, Entin-Meer M, et al. Characterization of structurally distinct, isoformselective phosphoinositide 3'-kinase inhibitors in combination with radiation in the treatment of glioblastoma. Mol Cancer Ther. 2008;7:841-850

39 Jiang Z, Pore N, Cerniglia GJ, et al. Phosphatase and tensin homologue deficiency in glioblastoma confers resistance to radiation and temozolomide that is reversed by the protease inhibitor nelfinavir. Cancer Res. 2007;67:4467-4473

$40 \mathrm{Su} \mathrm{Y,} \mathrm{Li} \mathrm{G,} \mathrm{Zhang} \mathrm{X,} \mathrm{et} \mathrm{al.} \mathrm{JSI-124} \mathrm{inhibits} \mathrm{glioblastoma} \mathrm{multiforme} \mathrm{cell} \mathrm{proliferation}$ through G(2)/M cell cycle arrest and apoptosis augment. Cancer Biol Ther. 2008;7:1243-1249 41 Fujita M, Zhu X, Sasaki K, et al. Inhibition of STAT3 promotes the efficacy of adoptive transfer therapy using type-1 CTLs by modulation of the immunological microenvironment in a murine intracranial glioma. J Immunol. 2008;180:2089-2098

42 de la Iglesia N, Konopka G, Puram SV, et al. Identification of a PTEN-regulated STAT3 brain tumor suppressor pathway. Genes Dev. 2008;22:449-462

43 de la Pena L, Burgan WE, Carter DJ, et al. Inhibition of Akt by the alkylphospholipid perifosine does not enhance the radiosensitivity of human glioma cells. Mol Cancer Ther. 2006;5:1504-1510

44 Tchirkov A, Khalil T, Chautard E, et al. Interleukin-6 gene amplification and shortened survival in glioblastoma patients. Br J Cancer. 2007;96:474-476

45 Tchirkov A, Rolhion C, Bertrand S, Dore JF, Dubost JJ and Verrelle P. IL-6 gene amplification and expression in human glioblastomas. Br J Cancer. 2001;85:518-522

46 Chakravarti A, Seiferheld W, Tu X, et al. Immunohistochemically determined total epidermal growth factor receptor levels not of prognostic value in newly diagnosed glioblastoma multiforme: report from the Radiation Therapy Oncology Group. Int J Radiat Oncol Biol Phys. 2005;62:318-327

47 Maher EA, Furnari FB, Bachoo RM, et al. Malignant glioma: genetics and biology of a grave matter. Genes Dev. 2001;15:1311-1333

48 Schuurbiers OC, Kaanders JH, van der Heijden HF, Dekhuijzen RP, Oyen WJ and Bussink J. The PI3-K/AKT-pathway and radiation resistance mechanisms in non-small cell lung cancer. J Thorac Oncol. 2009;4:761-767

49 Castellino RC and Durden DL. Mechanisms of disease: the PI3K-Akt-PTEN signaling node--an intercept point for the control of angiogenesis in brain tumors. Nat Clin Pract Neurol. 2007;3:682-693

\section{Captions}

Fig. 1. (A-H) Clonogenic survival curves of human malignant glioma cell lines. Cells were irradiated during the exponential growth phase and survival data were obtained from standard clonogenic assays. Data are represented by their mean \pm standard error and are fitted to the linear-quadratic model. Linear quadratic relation : $y=e-\left(\alpha D+\beta D^{2}\right)$. 
Fig. 2. Akt and STAT3 basal signaling pathways activation. A, Cells in were harvested during exponential growth phase and thirty micrograms of total proteins were loaded per lane and electrophoresed by SDS-PAGE. Transfer membranes were immunoblotted with antiSTAT3, anti-Akt, anti-pSTAT3-Tyr705, anti-pAkt-Ser473. To ensure equal protein, loading the blots were stripped and reprobed with anti- $\beta$-actin antibody. The blot is representative of three independent experiments with consistent results. $\boldsymbol{B}$ and $\boldsymbol{C}$, Densitometric analyses of the blots are presented as relative ratios of phosphoprotein/total protein. Data were plotted as mean values \pm standard error of triplicate determinations (arbitrary units).

\section{Fig. 3. Impact of Akt pathway down modulation on SF763 cells.}

$\boldsymbol{A}$, Cells were treated with Akt inhibitor IV during $7 \mathrm{~h}$, then harvested. Total cell extracts were electrophoresed by SDS-PAGE, followed by immunoblotting with anti-Akt, anti-Akt-Ser 473 and with anti- $\beta$-actin antibody. $\boldsymbol{B}$, Clonogenic survival of SF763 cell line exposed to a concentration range of Akt inhibitor IV. One representative experiment performed in triplicate is shown. $\boldsymbol{C}$, Clonogenic survival of SF763 cell line exposed to $0,2 \mu \mathrm{M}$ of Akt inhibitor IV during $24 \mathrm{~h}$. After $7 \mathrm{~h}$ of treatment, cells were irradiated to $4 \mathrm{~Gy}$ and surviving fraction was compared with that of control (DMSO). D, Clonogenic survival of SF763 cell line exposed to $0,2 \mu \mathrm{M}$ of Akt inhibitor IV during $24 \mathrm{~h}$. After $7 \mathrm{~h}$ of treatment cells were irradiated to 0 to 10 Gy and the surviving fraction was compared with that of control (DMSO). One representative of three independent experiments (performed in triplicate) is shown. 


\section{Fig. 4. Impact of Akt pathway down modulation on SF767 cells.}

$\boldsymbol{A}$, Cells were treated with Akt inhibitor IV during $7 \mathrm{~h}$, then harvested. Total cell extracts were electrophoresed by SDS-PAGE, followed by immunoblotting with anti-Akt, anti-Akt-Ser 473 and with anti- $\beta$-actin antibody. $\boldsymbol{B}$, Clonogenic survival of SF767 cell line exposed to a concentration range of Akt inhibitor IV. One representative experiment performed in triplicate is shown. $\boldsymbol{C}$, Clonogenic survival of SF767 cell line exposed to $0,1 \mu \mathrm{M}$ of Akt inhibitor IV during $24 \mathrm{~h}$. After $7 \mathrm{~h}$ of treatment, cells were irradiated to 2 Gy and surviving fraction was compared with control (DMSO). $\boldsymbol{D}$, Clonogenic survival of SF767 cell line exposed to $0,1 \mu \mathrm{M}$ of Akt inhibitor IV during 24h. After $7 \mathrm{~h}$ of treatment cells were irradiated to 0 to $10 \mathrm{~Gy}$ and the surviving fraction was compared with that of control (DMSO). One representative of three independent experiments (performed in triplicate) is shown.

\section{Fig. 5. Impact of STAT3 pathway down modulation on SF763 cells.}

A and D. Cells were treated with JSI-124 (7h) or with anti-gp130 blocking antibody (24h). Total proteins were electrophoresed by SDS-PAGE, followed by immunoblotting with antiSTAT3, anti-pSTAT3-Tyr705 and anti- $\beta$-actin antibody. $\boldsymbol{B}$, Clonogenic survival of SF763 cell line exposed $24 \mathrm{~h}$ to a concentration range of JSI-124. One representative experiment performed in triplicate is shown. $\boldsymbol{C}$, Clonogenic survival of SF763 cell line exposed to $0,01 \mu \mathrm{M}$ of JSI-124 during $24 \mathrm{~h}$. After $7 \mathrm{~h}$ of treatment cells were irradiated to $4 \mathrm{~Gy}$ and the surviving fraction was compared with that of control (DMSO). One representative of three independent experiments (performed in triplicate) is shown. $\boldsymbol{E}$, Clonogenic survival of SF763 cell line exposed to blocking anti-gp130 or to control (IgG2a) antibody when cells were attached in flasks ( $8 \mathrm{~h}$ after seeding), before or after irradiation. Cells were irradiated to $4 \mathrm{~Gy}$ and the surviving fraction was compared with that of control (IgG2a). Representative experiment performed in triplicate is shown. 
Fig. 6. Impact of STAT3 pathway down modulation on SNB19 cells.

$\boldsymbol{A}$, Cells were treated with anti-gp130 blocking antibody (24h). Total proteins were electrophoresed by SDS-PAGE, followed by immunoblotting with anti-STAT3, antipSTAT3-Tyr705 and anti- $\beta$-actin antibody. $\boldsymbol{B}$, Clonogenic survival of SNB19 cell line exposed to blocking anti-gp130 or to control (IgG2a) antibody when cells were attached in flasks ( $8 \mathrm{~h}$ after seeding). Cells were irradiated to $2 \mathrm{~Gy}$ and the surviving fraction was compared with that of control (IgG2a). Representative experiment performed in triplicate is shown. 
Figure 1
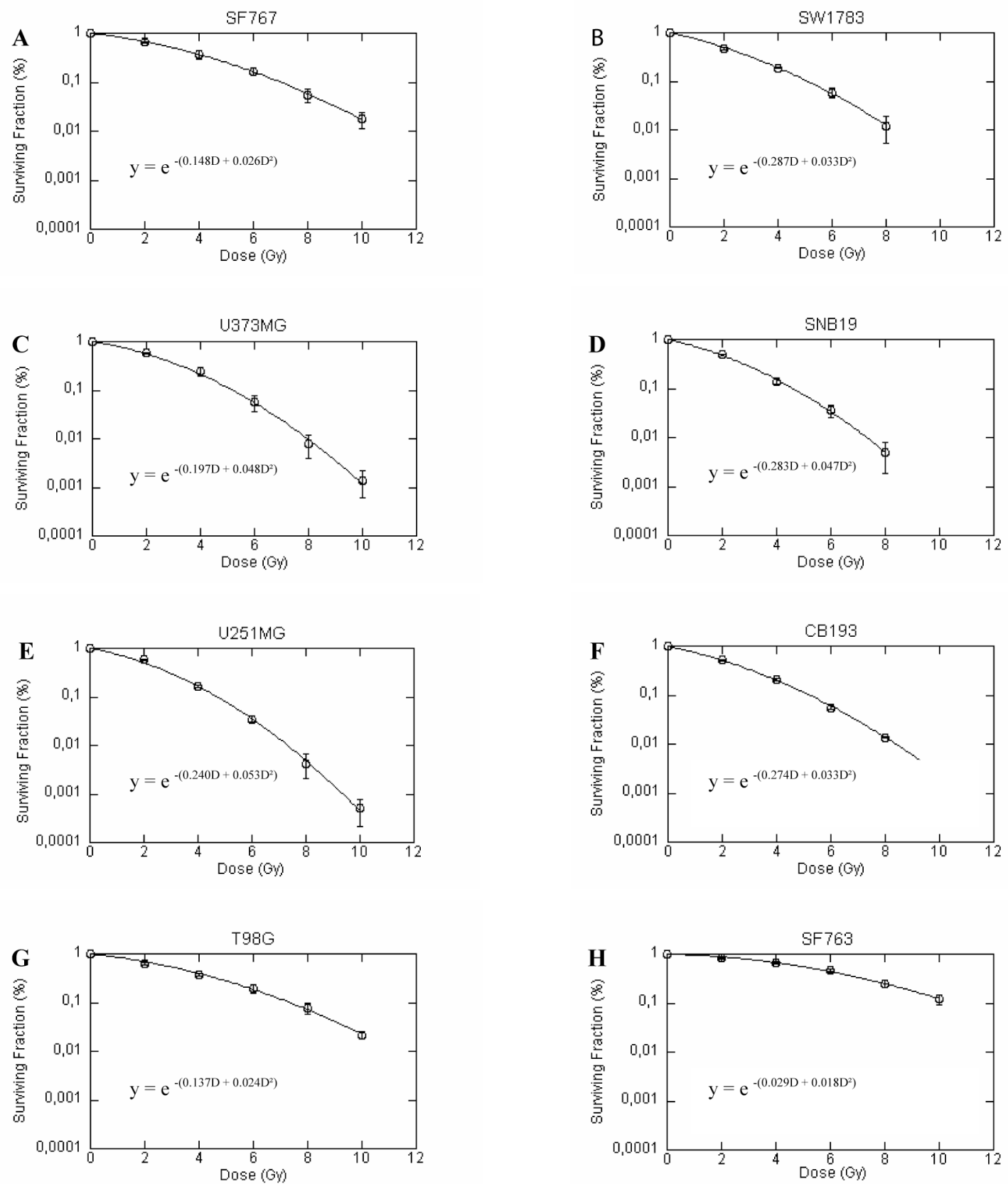
Figure 2

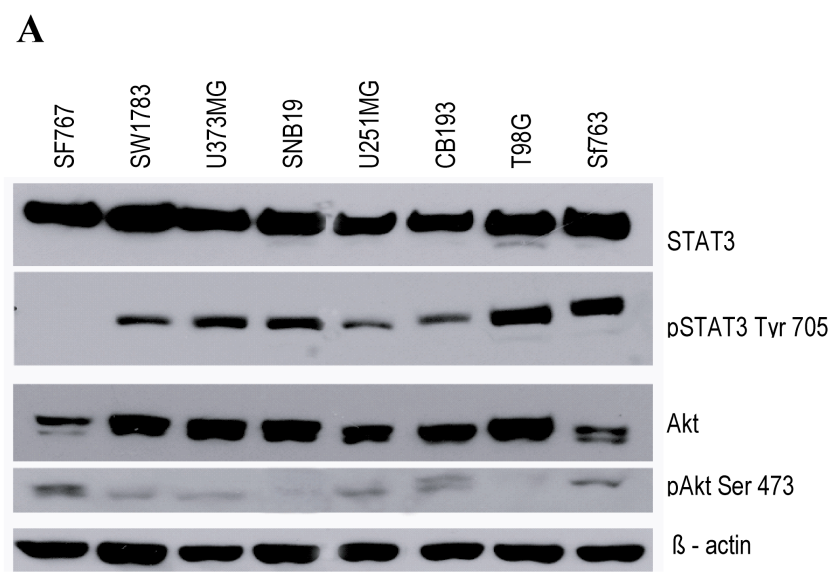

B

pSTAT3/STAT3

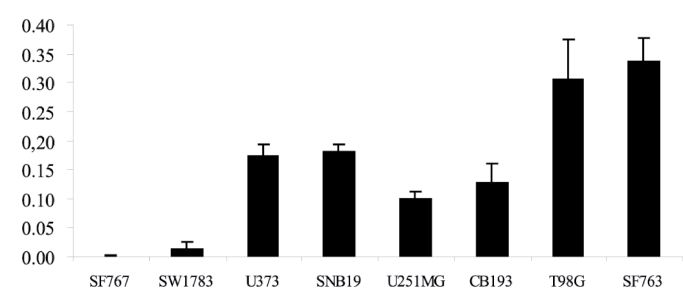

C

pAkt/Akt

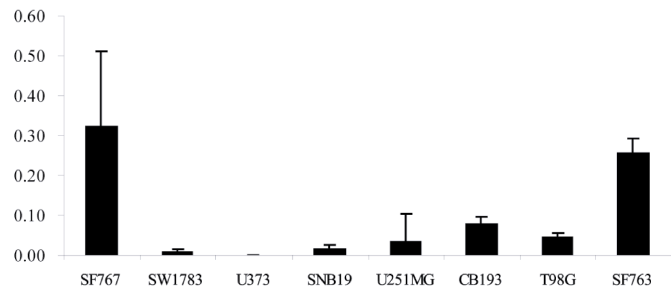


Figure 3

A

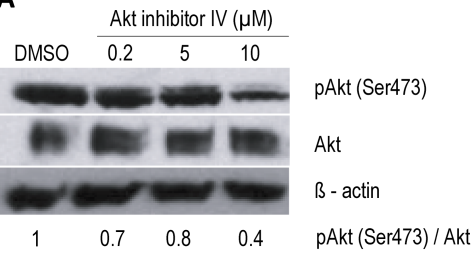

B

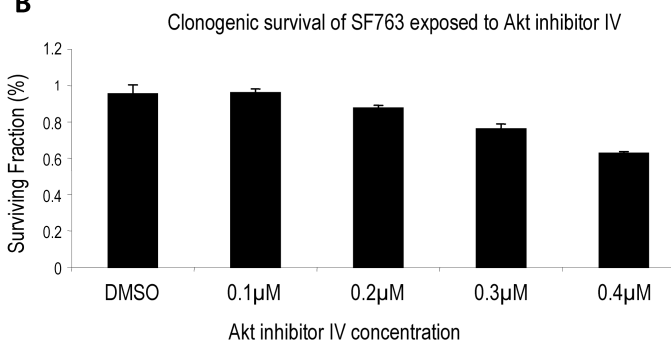

D Clonogenical survival of SF763 exposed to $0.2 \mu \mathrm{M}$

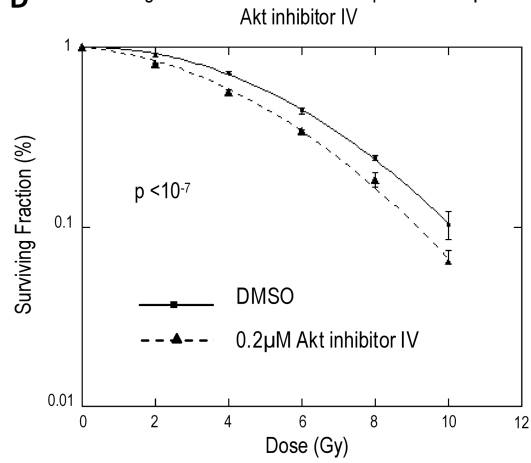

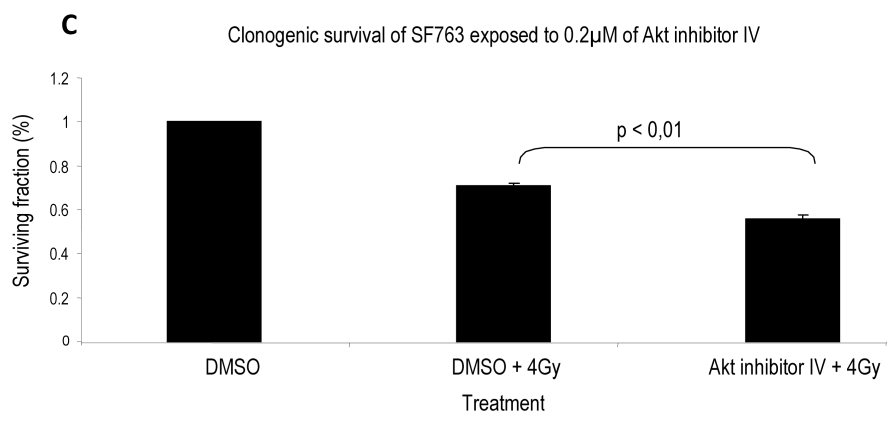


Figure 4

A

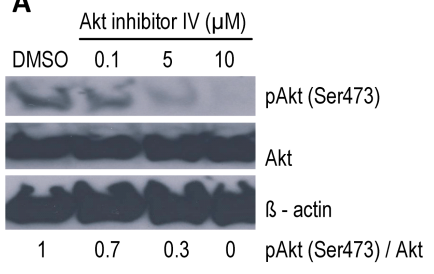

B Clonogenic survival of SF767 exposed to Akt inhibitor IV

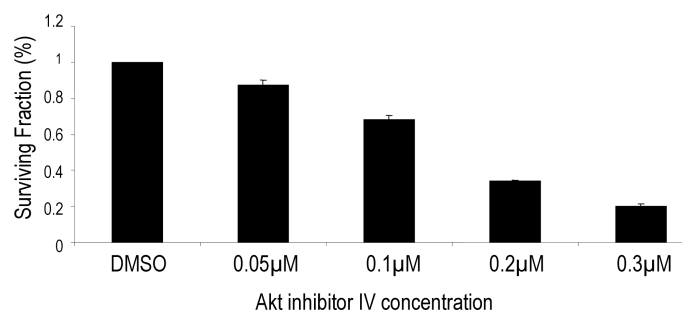

C

Clonogenic survival of SF767 exposed to $0.1 \mu \mathrm{M}$ of Akt inhibitor IV

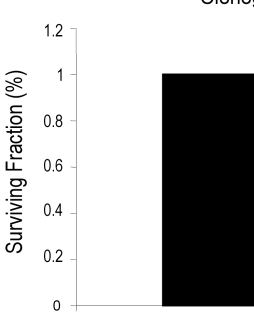

DMSO

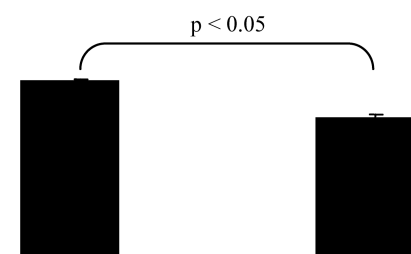

$\mathrm{DMSO}+2 \mathrm{~Gy}$ treatment
Akt inhibitor IV + 2Gy
D Clonogenical survival of SF767 exposed to $0.1 \mu \mathrm{M}$ Akt inhibitor IV

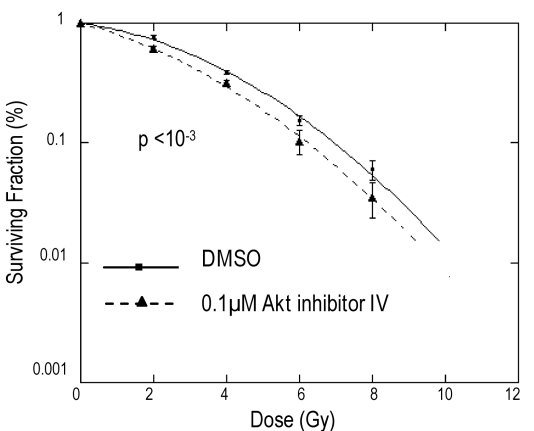


Figure 5

A

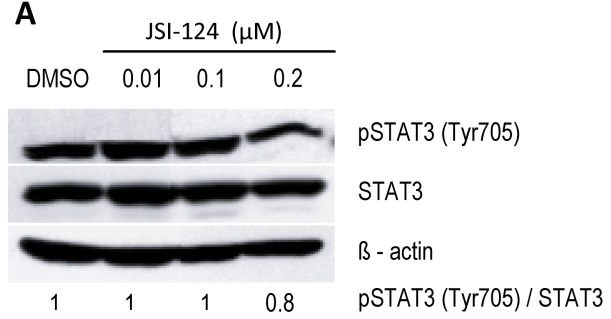

C Clonogenic survival of SF763 exposed to $0.01 \mu \mathrm{M}$ JSI-124

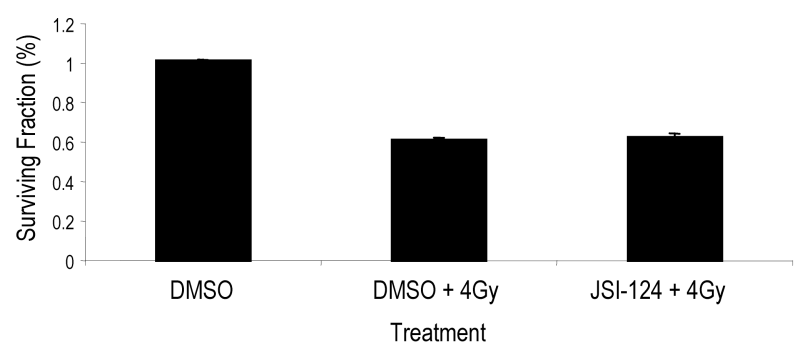

E

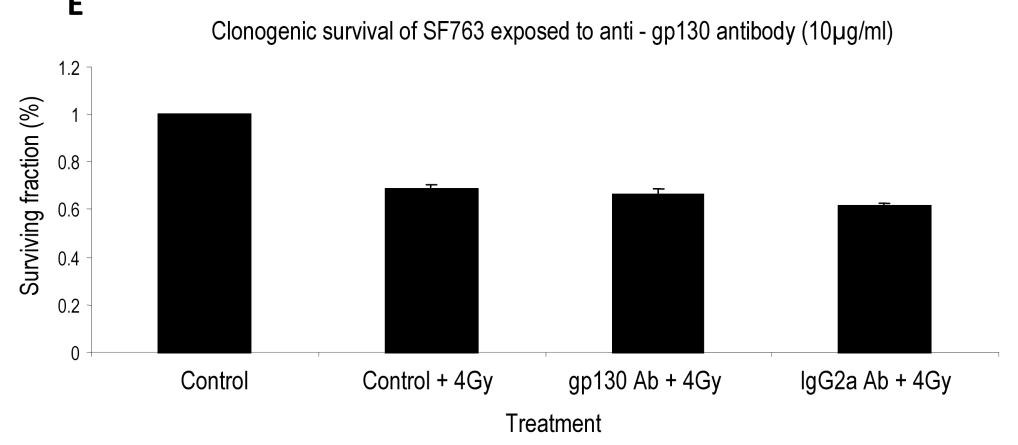

B Clonogenic survival of SF763 exposed to JSI-124

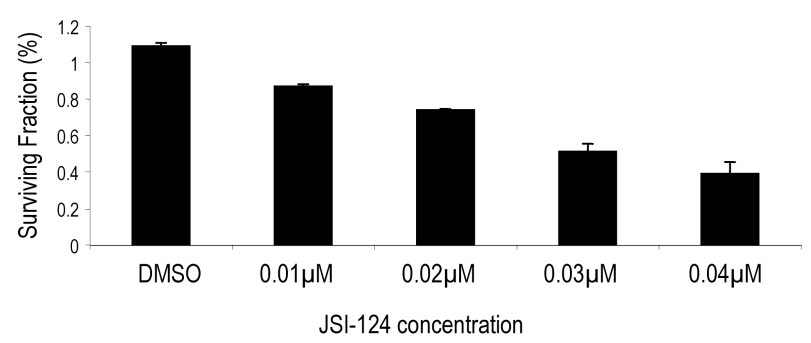

D

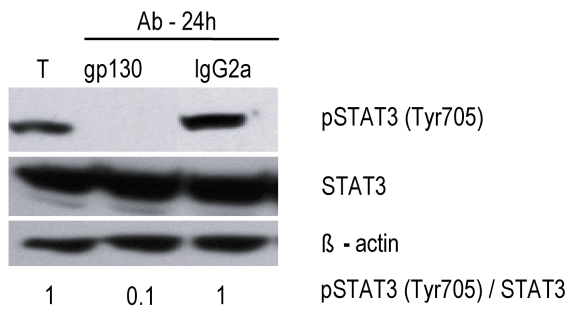


Figure 6

A

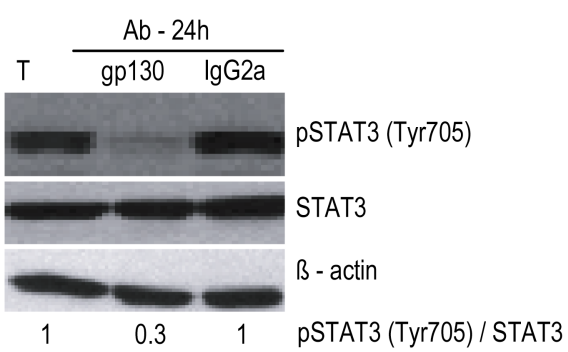

B

Clonogenic survival of SNB19 exposed to anti-gp130 antibody (10 $\mathrm{\mu g} / \mathrm{ml})$

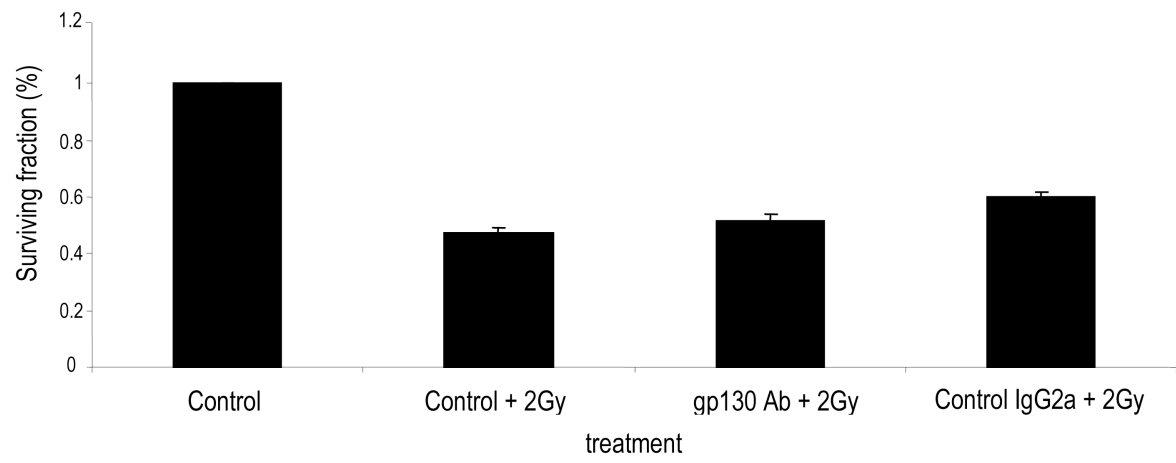


Table 1. Radiosensitivity of 8 tumor cell lines.

\begin{tabular}{lllll}
\hline cell line & Origin & SF2* & AUC $(G y)$ & PE $^{\dagger \dagger}$ \\
\hline SF767 & glioblastoma & $0.68 \pm 0.05$ & 3.6 & 0.20 \\
SW1783 & astrocytoma grade III & $0.46 \pm 0.03$ & 2.4 & 0.05 \\
U373MG & glioblastoma & $0.58 \pm 0.03$ & 2.8 & 0.13 \\
SNB19 & glioblastoma & $0.50 \pm 0.01$ & 2.3 & 0.12 \\
U251MG & glioblastoma & $0.58 \pm 0.01$ & 2.6 & 0.28 \\
CB193 & glioma grade III & $0.52 \pm 0.02$ & 2.6 & 0.07 \\
T98G & glioblastoma & $0.64 \pm 0.05$ & 3.6 & 0.09 \\
SF763 & glioblastoma & $0.83 \pm 0.04$ & 5.5 & 0.17 \\
\hline
\end{tabular}

*SF2 : Survivin g Fraction at $2 \mathrm{~Gy} ;{ }^{\dagger} \mathrm{AUC}$ : Area Under the survival Curve; ${ }^{\dagger} \mathrm{PE}$ : Plating Efficiency 